\title{
Hommage à Isabel Boussard-Decaris
}

\section{François Clerc, Hélène Delorme et Claude Servolin}

\section{(2) OpenEdition \\ Journals}

Édition électronique

URL : http://journals.openedition.org/economierurale/572

DOI : $10.4000 /$ economierurale. 572

ISSN : 2105-2581

Éditeur

Société Française d'Économie Rurale (SFER)

Édition imprimée

Date de publication : 1 mars 2006

Pagination : 04-05

ISSN : 0013-0559

\section{Référence électronique}

François Clerc, Hélène Delorme et Claude Servolin, « Hommage à Isabel Boussard-Decaris », Économie rurale [En ligne], 291 | Janvier-février 2006, document 1, mis en ligne le 05 janvier 2008, consulté le 15 septembre 2020. URL : http://journals.openedition.org/economierurale/572 


\section{Hommage à Isabel Boussard Decaris}

Par François CLERC • ancien président de la SFER

Hélène DELORME • chercheur associé au CERI

Claude SERVOLIN • directeur de recherche de I'INRA

sabel Boussard-Decaris nous a quittés le 24 mars 2006.

Nous n'oublierons pas cette personnalité attachante dont les facettes apparaissaient une fois tombée la réserve dressée par sa timidité. Sa générosité était précieuse pour ses collègues qui trouvaient toujours auprès d'elle écoute, avis et conseils. Son humour surprenait par sa capacité à faire sourire les choses, les gens et les situations. Son profond goût des choses de l'esprit et de l'art en faisait une intellectuelle qui savait prendre de la distance avec les petites vanités et les péripéties mondaines.

Nous n'oublierons pas non plus cette historienne du temps présent qui s'est montrée une remarquable observatrice des rapports complexes que les agriculteurs entretiennent avec le politique. Dès sa thèse consacrée à la Corporation paysanne du régime de Vichy, cette acuité dans l'observation se révèle. Le sujet était difficile, concernait une période noire de I'histoire du pays, peu étudiée et mal connue. Menée sans complaisance ni préjugé, appuyée sur la rigueur de la méthode historique, son enquête met au jour l'attitude politique paradoxale des grands agrariens qui animèrent la Corporation paysanne. Ces dirigeants se pensaient comme des entrepreneurs capables de jouer le marché et revendiquaient une organisation autonome du secteur dans le cadre corporatiste du métier. Mais ils ne purent échapper à la nécessité d'une politique agricole et durent accepter une agriculture à économie administrée et chapeautée par un corporatisme d'État. Isabel Boussard met magistralement en lumière l'ironie de l'histoire de ces dirigeants qui voulaient faire une organisation "libre " et se retrouvèrent embrigadés dans une corporation présidée par le Ministre de l'agriculture.

L'économie de guerre et l'autoritarisme de «l'État français » ont certes contribué à cet aboutissement mais ils n'expliquent pas tout car le paradoxe se retrouve une fois la paix revenue. Après 1945, les grands agriculteurs restent partagés par la même contradiction qui est un des fondements de leur spécificité et permet de parler d'agrarianisme. S'ils revendiquent de jouer le marché, c'est à la condition que l'État régule leurs relations avec les autres secteurs économiques en fixant les prix à la production ou, aujourd'hui, en accordant les aides directes nécessaires pour compenser l'instabilité des prix. Ces producteurs se voient comme un groupe professionnel autonome mais ils recherchent la reconnaissance de l'État qui confère à leurs organisations la légitimité, l'autorité et les financements sans lesquels elles ne peuvent rien.

Cette particularité des relations au politique des agriculteurs tient une large place dans l'intérêt que leur a porté Isabel Boussard. Nous n'oublierons pas I'analyste attentive et assidue des comportements électoraux des agriculteurs, lors des élections politiques générales et lors des élections professionnelles organisées pour désigner les dirigeants des Chambres d'agriculture. L'originalité des agriculteurs se manifeste dans les deux types de scrutins, principalement par des taux de 
participation nettement plus élevés que ceux des autres catégories de citoyens et de professionnels. Nous n'oublierons pas la grande disponibilité d'Isabel Boussard face aux demandes des revues et des organisations professionnelles agricoles qui souhaitaient s'informer sur le vote paysan. Elle n'hésitait pas alors à partager ses analyses car la vulgarisation était, selon elle, partie intégrante du travail scientifique.

Nous n'oublierons pas qu'lsabel Boussard a été un des piliers de la SFER à laquelle elle a porté longtemps un concours aussi régulier qu'efficace sans jamais se mettre en avant car elle avait la modestie du bénévolat. Membre assidue du bureau, elle fut l'une des animatrices de la célébration du cinquantenaire de l'association à travers sa participation à l'équipe éditoriale du numéro spécial d'Économie rurale publié pour fêter la date. Elle y a toujours soutenu les projets d'analyse du mouvement professionnel agricole, notamment en s'associant tout récemment à l'équipe de préparation du colloque à venir sur les syndicats agricoles. Elle contribuait aussi, par une participation régulière et active, à l'animation du séminaire de politique agricole qu'avait créé son mari Jean-Marc Boussard.

Nous n'oublierons pas le climat chaleu- reux qu'elle faisait régner dans sa famille et qui n'était pas le moindre des charmes d'Isabel Boussard. Elle avait toujours pour son mari, ses proches et ses familiers un regard aussi affectueux et aimant que spirituel et compréhensif. C'est parce qu'elle savait ce qu'elle voulait et ce qu'elle valait qu'elle pouvait être tolérante pour les autres. Et aussi reconnaître et saluer leurs mérites. Nous n'oublierons pas le magnifique ouvrage publié en 2005 avec le concours de l'Académie du Var, dont Isabel Boussard était membre, pour honorer la mémoire de son père, Albert Decaris, un des plus talentueux graveurs de timbre du $x x^{e}$ siècle. Elle y a présenté et catalogué, avec l'aide de son mari, les grandes gravures moins connues mais tout aussi belles et « singulières » que les miniatures des timbres.

La disparition si brutale et prématurée d'Isabel Boussard Decaris emplit ses amis d'une nostalgie d'autant plus forte que la place qu'elle laisse risque de rester longtemps vide. Les études sur l'agriculture ne se voient-elles pas confinées aujourd'hui dans une sphère technique sous l'effet d'une double réduction, disciplinaire, par la prédominance que tend à prendre l'économie, institutionnelle, par le retrait plus ou moins avoué des organismes généralistes de recherche et d'enseignement ? 